\title{
Psychological needs and mental health in women aged $\geq 65$ years after cardiac surgery: an exploratory study
}

\author{
Bisogni e salute psicologica nelle donne over 65 \\ cardioperate: uno studio esplorativo
}

\author{
Ombretta Omodeo1, Elena Fiabane1, Ines Giorgi1, Claudia Grandis", \\ Alessandra Gualco2, Monica Ceresa2
}

\begin{abstract}
Psychological needs and mental health in women aged $\geq 65$ years after cardiac surgery: an exploratory study. O. Omodeo, E. Fiabane, I. Giorgi, C. Grandis, A. Gualco, M. Ceresa.

Background. Recent developments in cardiac care have led to an increase survival even among elderly cardiac patients. Previous studies showed that women have worse health related outcomes compared with men. The main aims of this study are to assess psychological needs and factors promoting mental health among women aged $\geq 65$ years following heart surgery.

Methods. 74 consecutive women aged $\geq 65$ years and referred to a cardiac rehabilitation unit in Northern Italy after heart surgery were enrolled in this exploratory study. Psychological questionnaires exploring cognitive functioning, psychological needs, anxiety, depression, physical and mental health status, self-esteem were administered by a psychologist to each patient using a face-to-face interview.
\end{abstract}

Results. The main areas of psychological needs reported by patients were relational and emotional support, assistance and treatment, information about diagnosis and future conditions and information concerning economic-insurance issues. Multivariate linear regression analysis showed that factors significantly associated with patients' mental health were anxiety $(p=0.01)$ and locus of control $(p=0.01)$.

Conclusions. In order to improve older cardiac women's mental health after cardiac surgery is important to offer tailored rehabilitative interventions able to meet their specific needs such as the management of anxiety symptoms and loss of control, the need to regain the family role, the need of more information concerning the diagnosis and prognosis and emotional support.

Keywords: older women, cardiac surgery, psychological needs, mental health, cardiac rehabilitation.

Monaldi Arch Chest Dis 2013; 80: 35-41.

\footnotetext{
1 Psychological Unit, Salvatore Maugeri Foundation, Work and Rehabilitation, IRCCS, Scientific Institute of Pavia.

2 Cardiac Rehabilitation Unit, Salvatore Maugeri Foundation, Work and Rehabilitation, IRCCS, Scientific Institute of Pavia.
}

Corresponding author: Ombretta Omodeo, Psychological Unit, Salvatore Maugeri Foundation, Work and Rehabilitation, IRCCS, Scientific Institute of Pavia, Via Maugeri 10, I-27100 Pavia, Italy; Phone: 0382.592951; Fax: 0382.592947; E-mail address: ombretta.omodeo@fsm.it

\section{Introduction}

The progressive aging of the general population and improvements of cardiac medical treatments and surgical interventions have contributed to create a large population of older adults $(\geq 65$ years of age) with cardiovascular diseases $[1,2]$. Mortality for cardiovascular diseases (CVD) has decreased in most European countries during the last several decades, but it still is the main cause of death, accounting for 1.9 million deaths each year (43\% of deaths in women and $36 \%$ of deaths in men) [3]. Recent studies [1, 4], showed that that the burden of coronary heart diseases is shifting from middle-aged men towards women and elderly patients. Therefore, cardiac rehabilitation and quality of life of older cardiac patients are important issues of medical practice. Cardiac rehabilitation (CR) generally consisted of patient's medical assessment, psychological and occupational evalua- tion, nutritional counselling, personalized physical exercises, health educational and behaviour change activities [5]. CR is recognized as crucial component of CVD patients' care since several studies showed that it is useful and effective for cardiac risk and disability reduction, healthy behaviour promotion and quality of life improvement, also among elderly cardiac patients $[7,8,9,10]$. Recent systematic reviews and meta-analyses confirmed the beneficial effects of therapeutic and preventive cardiac interventions on physiological risk factors and distress [11, 12]. Several researches showed that the enrollment in CR after heart surgery is particularly low for woman in comparison with men $[13,14,15]$. A possible explanation for these findings is that women are characterized by some barriers that can influence their attendance to $\mathrm{CR}$, such as increased age, higher depression and anxiety, greater co-morbidity, greater risk for subjective cognitive difficulties, lower exercise capacity, 
lower social support, poorer psychological adjustment, low socioeconomic status, worse health related quality of life (HRQL) and are more like to be unemployed or retired then men $[13,15,16,17,18$, 25]. Particular attention should be paid to older cardiac women because they have additional emotional and physical needs that should be taken into account in order to improve their participation and adherence to cardiac rehabilitation interventions. For example, older women had lower exercise capacity, they are often widowed or are primary caregiver of an elderly husband, are more likely to live alone, are at higher risk of psychological distress, have a greater need for instrumental support and social support and reported needs for tailored rehabilitation programs, compared with men [20,21].

Although the benefits of secondary prevention, only few studies so far have investigated the specific psychosocial needs of cardiac elderly patients who are attending cardiac rehabilitation programs [2]. Therefore, there is an urgent necessity of understanding psychological needs and mental health status of older women with heart diseases in order to develop tailored interventions, based on their specific needs and able to improve their quality of life.

The aims of this study are: a) to assess psychological needs and psychological characteristics of women aged $\geq 65$ years who are attending cardiac rehabilitation following heart surgery; b) to explore whether patients aged 65-75 and those aged $>75$ differ in psychosocial characteristics and c) to identify factors associated with older patients' mental health status in order to improve cardiac rehabilitation programs.

\section{Methods}

\section{Sample and Procedure}

Inpatients referred to the cardiac rehabilitation unit of the Salvatore Maugeri Foundation, Institution of Care and Research (IRCSS) of Pavia, were enrolled between January, 2010 and November, 2012. The inclusion criteria were: recent coronary bypass surgery $(\mathrm{CABG})$ or cardiac valve surgery $(\mathrm{CV})$; age $\geq 65$; female gender; Mini-Mental State Examination (MMSE) > 18; able to read and write Italian.

Cardiac rehabilitation (CR) aims at the stabilization of the cardiac disease and the control of modifiable cardiovascular risk factors in order to improve functional capacity and restore patients' physiological, psychological and social status. The cardiac rehabilitation program of our institute is tailored for older women and it consists of three/four weeks of personalized physiotherapy on the basis of patients' fragility, modification of CVD risk factors (e.g., smoking habit, dyslipidemia, overweight/obesity), educational and psychological counseling and occupational therapy. The main aim is to improve patients' independency and mobility in order to promote and facilitate their return to activities of daily living, with particular regard to household activities. Additionally, participants of this study were invited to return as outpatients at two months follow-up after discharge and these data collection process is still in progress.
Data were collected at the beginning of the cardiac rehabilitation. Psychological intervention included individual psychological counselling to provide general information on psychological activities and rehabilitative programs, and to assess hospitalized patients' needs. Moreover, the psychologist administered to participants the psychological questionnaires using a face-to-face interview.

Of the original 84 included patients, a total of 74 $(88.09 \%)$ were eligible for this study: $2(2.38 \%)$ had a MMSE $<18,1(1.19 \%)$ was transferred for a heart attack, $1(1.19 \%)$ was illiterate, $4(4.76 \%)$ refused to participated and $2(2.38 \%)$ were excluded because of other reasons.

\section{Measures}

Questionnaires were administered to patients by a psychologist using a face-to-face interview in order to facilitate patients' understanding to questions and to improve their motivation to take part in the study.

Mini-Mental State Examination (MMSE) [22, 23]. MMSE is a 10-minute measure of impaired thinking, widely used with old populations and in clinical settings. The maximum score is 30 when all items are correctly answered. Traditionally, a MMSE cutoff score of 24 have been used to categorized cognitively intact or impaired subjects [24]. The total score is adjusted for age and education level.

Needs Evaluation Questionnaire (NEQ) [25, 26]. It is a short self-report questionnaire composed of 23 items which investigates hospitalized patients' most common needs: informative needs (9 items) needs related to assistance and care (3 items), relational needs ( 3 items), needs for a psychoemotional support (3 items) and material needs (3 items) [20]. The answers are dichotomized into present or absent of the need (Yes/No). The questionnaire was originally designed in an oncologic setting but can be extended to other healthcare settings where the diagnosis and the prognosis may interfere with patients' quality of life.

Anxiety and Depression Short Scale (AD-R) [27]. It is an instrument recommended for the screening of patients' depressive and anxious symptoms in hospital rehabilitative settings. It is composed of two scales: the short version of the Depression Questionnaire [28, 29] and the STAI-X3 [30] which is a short version of the STAI-X1 [31]. Clinically important depressive symptoms for women were defined as a DQ-15 score $\geq 8$. Clinically important state anxiety for women was defined as a STAI-X3 score $\geq 25$.

Short form Health Survey (SF-12) [32, 33]. It is a short version of the well-known SF-36 [34] which is one of the most used instruments to measure health-related quality of life. It is composed of 12 questions and it provides two summary scores: the Physical Component Summary (PCS) and the Mental Component Summary (MCS). High score indicate good physical and health status.

Locus of Control of Behaviour (LCB) [35, 36]. It is a 17-item Likert-type scale to measure the extent to which a person perceives events as a consequence of his own behavior and believes that they are potentially under personal control (internal locus of 
control), or instead that events are determined by fate or outside forces that are beyond his own personal control (external locus of control). All items are evaluated on a six-point Likert scale (from $0=$ strongly disagree to $5=$ strongly agree). High total scores indicate externality.

Rosenberg Self-Esteem Scale (RSE) [37, 38]. It is a short self-report questionnaire composed of 10 easy items which ask patient to evaluate to which extent he is satisfied of himself, he is proud of himself, he consider himself as a person of worth or instead a useless person, good for nothing. Items are answered on a four point scale from $0=$ strongly disagree to $3=$ strongly agree. The higher score, the higher the self-esteem.

\section{Statistical analysis}

Descriptive analyses were conducted to characterize the study sample. Patients aged between 65-75 and patients aged $>75$ were compared on socio-demographic, clinical and psychological variables using Mann-Whitney test for continuous variables and Chi-Square test for categorical variables. Univariate linear regression analysis was performed to explore factors associated with mental health status. When a variable failed to demonstrate significant power in the univariate analysis $(p>0.10)$, it was excluded from further consideration and not included in the multivariate regression model. Multiple linear regression analysis was carried out to explore predictors of mental health status. All analyses were performed using SPSS for Windows, version 13.0. A $p$-value $<0.05$ was considered statistically significant.

\section{Results}

At the time of the admission, most of the 74 patients were between 75 and 88 years old $(52.7 \%)$, with a mean age of $75.26 \pm 5.42$. The majority of participants were widowed $(52.7 \%)$, with an elementary school level $(48.6 \%)$, in retirement $(73.0$ $\%)$ and with a recent cardiac valve surgery (63.5\%). Participants referred that they do not live alone $(55.4 \%)$ and that their primary caregivers are the

\begin{tabular}{llcc}
$\begin{array}{l}\text { Table 1. - Classic CVD risk factors for the total sample } \\
(\mathrm{n}=74)\end{array}$ & & $\mathbf{n}$ & $\%$ \\
\hline \multicolumn{1}{l}{ Smoking } & Current & 8 & 10.8 \\
& In the past & 8 & 10.8 \\
& Never & 58 & 78.4 \\
\hline Family history of heart disease & Yes & 22 & 29.7 \\
& No & 52 & 70.3 \\
\hline Dyslipidemia & Yes & 28 & 37.8 \\
& No & 46 & 62.2 \\
\hline Diabetes mellitus & Yes & 24 & 32.4 \\
& No & 50 & 67.6 \\
\hline Hypertension & Yes & 60 & 81.1 \\
& No & 14 & 18.9 \\
\hline
\end{tabular}

husband $(47.3 \%)$ or the sons $(45.5 \%)$. Most patients referred that they either do not use psychotropic drug for insomnia $(63.5 \%)$ or psychotropic drug for mood $(94.6 \%)$. In relation to the classic CVD risk factors (Table 1), the majority of the sample referred that they currently do not smoke $(78.4 \%)$, they have no family history of heart disease $(70.3 \%)$, or dyslipidemia $(62.2 \%)$, or diabetes mellitus $(67.6 \%)$, but most of the women have hypertension $(81.1 \%)$.

Results from the Needs Evaluation Questionnaire showed that psychological needs most frequently referred by older cardiac women were: "I need to feel more useful within my family" (25.0 $\%$ ), "I need more information about my future condition" (21.7\%), "I need to speak with people who have the same experience" (20.0\%), "I need my symptoms (pain, nausea, insomnia, etc.) to be better controlled" (18.3\%), "I need more information about my diagnosis (15.0\%), "I need to be more reassured by the clinicians" and "I need to have more economic-insurance information (tickets, invalidity, etc.) $(13.0 \%)$ (Table 2$)$. We only showed needs referred by more than $10 \%$ of the total sample.

Table 2. - Psychological needs of elderly cardiac women $(n=60)^{*}$

\begin{tabular}{|c|c|c|c|}
\hline Rank & $\%(\mathbf{n})$ & Psychological needs & Area \\
\hline 1 & $25.0(15)$ & I need to feel more useful within my family & Relational need \\
\hline 2 & $21.7(13)$ & I need more information about my future condition & Informational need \\
\hline 3 & $20.0(12)$ & I need to speak with people who have the same experience & Need for support \\
\hline 4 & $18.3(11)$ & I need my symptoms (pain, nausea, insomnia, etc.) to be better controlled & $\begin{array}{l}\text { Need related to assistance } \\
\text { and treatment }\end{array}$ \\
\hline 5 & $15.0(9)$ & I need more information about my diagnosis & Informational need \\
\hline 6 & $13.0(8)$ & I need to be more reassured by the clinicians & $\begin{array}{l}\text { Need related to assistance } \\
\text { and treatment }\end{array}$ \\
\hline 6 & $13.0(8)$ & I need to have more economic-insurance information (tickets, invalidity, etc.) & Financial need \\
\hline
\end{tabular}


Results from MMSE showed that the mean score for the total sample was $25.94(\mathrm{SD}=3.62)$ and among these, $35.1 \%$ had a mild cognitive impairment (score $>18$ and $<24$ ). The mean score for the Depression Questionnaire was $5.41(\mathrm{SD}=2.79)$ and the average of clinically depressed patients was $21.6 \%$ (score $\geq 8$ ). The mean score of STAI-X3 was 20.70 ( $\mathrm{SD}=5.94)$ with $21.6 \%$ of patients emerged as clinically anxious (score $\geq 25$ ). Descriptive statistics of all questionnaires and comparisons between the two age groups are reported in Table 3. Results showed that there was no statistically significant difference $(p>0.05)$ in psychological questionnaires between patients aged between 65 and 75 and the ones aged more than 75 years. Elderly patients were characterized by significant lower score in MMSE $(\mathrm{Z}=-2.44 ; p=0.01)$, are significantly more likely to be widowed $\left(\chi^{2}=5.20 ; p=0.02\right)$ and to use psychotropic drug for $\operatorname{mood}\left(\chi^{2}=5.20 ; p=0.05\right)$ compared to the women aged less than 75 years.

Regression analyses are shown in Table 4. Univariate linear regression analysis was used to identify factors associated with Mental health status of cardiac patients, measured by SF-12. Anxiety $(\beta=-0.51 ; p=<0.001)$, Depression $(\beta=-0.49$; $p<0.001)$, Locus of control $(\beta=-0.50 ; p<0.001)$,
Self-esteem $(\beta=0.38 ; p=0.001)$ and psychotropic drugs for insomnia $(\beta=-0.27 ; p=0.019)$ were significantly associated with Mental health status. Multivariate linear regression showed that significant factors associated with Mental health were Anxiety $(\beta=-0.37 ; p=0.010)$ and Locus of control $(\beta=-0.29 ; p=0.016)$.

\section{Discussion}

The first aim of this study was to assess psychological needs of cardiac women aged $\geq 65$ years who were attending cardiac rehabilitation following heart surgery. A recent study [21] found that cardiac rehabilitation programs did not meet the needs of many older patients and it suggested the importance of identifying patients' needs in order to implement more appropriate interventions.

Our results showed that the psychological needs most frequently referred by older cardiac women were related to the relational and emotional areas, such as the need to regain their family role, to speak and share their illness perception with other people who have the same experience. Previous studies [18, 20, 39] found that a major concern for older cardiac women was to regain their role as a homemaker despite their

Table 3. - Characteristics of women aged $65-75$ and aged over 75 after heart surgery $(n=74)$

\begin{tabular}{|c|c|c|c|c|c|c|c|c|}
\hline & \multicolumn{2}{|r|}{ Age 65-75 } & \multicolumn{2}{|r|}{ Age $>75$} & \multicolumn{2}{|r|}{ Total } & \multirow[b]{2}{*}{$\mathrm{Z}$ or $\chi^{2}$} & \multirow[b]{2}{*}{$p$} \\
\hline & $\mathbf{n}$ & M (SD) or \% & $\mathbf{n}$ & (M (SD) or \% & $\mathbf{n}$ & M (SD) or \% & & \\
\hline \multicolumn{9}{|l|}{ Education level } \\
\hline$\leq 5$ years & 21 & 45.7 & 25 & 54.3 & 46 & 62.2 & \multirow[t]{2}{*}{0.13} & \multirow[t]{2}{*}{0.71} \\
\hline$>5$ years & 14 & 50.0 & 14 & 50.0 & 28 & 37.8 & & \\
\hline \multicolumn{9}{|l|}{ Marital status } \\
\hline Married & 19 & 63.3 & 11 & 36.7 & 30 & 40.5 & \multirow[t]{2}{*}{5.20} & \multirow[t]{2}{*}{0.02} \\
\hline Widowed or not married & 16 & 36.4 & 28 & 63.6 & 44 & 59.5 & & \\
\hline \multicolumn{9}{|l|}{ Type of intervention } \\
\hline CABG & 11 & 40.7 & 16 & 59.3 & 27 & 36.5 & \multirow[t]{2}{*}{0.73} & \multirow[t]{2}{*}{0.39} \\
\hline Valve surgery & 24 & 51.1 & 23 & 48.9 & 47 & 63.5 & & \\
\hline \multicolumn{9}{|c|}{ Use of Psychotropic drug for insomnia } \\
\hline No & 24 & 51.1 & 23 & 48.9 & 47 & 63.5 & \multirow[t]{2}{*}{0.73} & \multirow[t]{2}{*}{0.39} \\
\hline Yes & 11 & 40.7 & 16 & 59.3 & 27 & 36.5 & & \\
\hline \multicolumn{9}{|c|}{ Use of Psychotropic drug for mood } \\
\hline No & 35 & 50.0 & 35 & 50.0 & 70 & 94.6 & \multirow{2}{*}{3.79} & \multirow{2}{*}{0.05} \\
\hline Yes & 0 & 0.0 & 4 & 100.0 & 4 & 5.4 & & \\
\hline \multicolumn{9}{|l|}{ Patient's Caregiver } \\
\hline Husband & 17 & 65.4 & 9 & 34.6 & 26 & 47.3 & \multirow[t]{2}{*}{1.63} & \multirow[t]{2}{*}{0.20} \\
\hline Others (sons, sisters) & 14 & 48.3 & 15 & 51.7 & 29 & 52.7 & & \\
\hline MMSE & 35 & $26.97(3.42)$ & 39 & $25.02(3.58)$ & 74 & $25.94(3.62)$ & -2.44 & 0.01 \\
\hline Depression & 35 & $5.40(2.88)$ & 39 & $5.41(2.75)$ & 74 & $5.41(2.79)$ & -0.26 & 0.79 \\
\hline Anxiety & 35 & $19.91(4.78)$ & 39 & $21.41(6.80)$ & 74 & $20.70(5.94)$ & -0.66 & 0.50 \\
\hline Self-esteem & 33 & $31.39(4.39)$ & 37 & $31.73(4.96)$ & 70 & $31.57(4.67)$ & -0.95 & 0.34 \\
\hline Locus of control & 31 & $34.32(11.41)$ & 32 & 34.47 (10.99) & 63 & $34.40(11.11)$ & -0.40 & 0.69 \\
\hline Physical health status & 34 & $43.61(7.57)$ & 38 & $32.09(9.29)$ & 72 & $33.28(8.56)$ & -1.49 & 0.13 \\
\hline Mental health status & 34 & $47.06(12.18)$ & 38 & 46.55 (11.17) & 72 & $46.79(11.57)$ & -0.19 & 0.84 \\
\hline
\end{tabular}


Table 4. - Factors associated with mental health status among older woman after heart surgery $(n=74)$

\begin{tabular}{|c|c|c|c|c|c|c|}
\hline & \multicolumn{6}{|c|}{ Mental health status } \\
\hline & \multicolumn{3}{|c|}{ Univariate Regression } & \multicolumn{3}{|c|}{ Multivariate Regression } \\
\hline & B & $\beta$ & $p$ & B & $\beta$ & $p$ \\
\hline Psychotropic drugs for insomnia & -6.56 & -0.27 & 0.019 & -4.22 & -0.17 & 0.12 \\
\hline Depression & -2.01 & -0.49 & $<0.001$ & -0.19 & -0.04 & 0.75 \\
\hline Anxiety & -0.99 & -0.51 & $<0.001$ & -0.75 & -0.37 & 0.010 \\
\hline Self-esteem & 0.96 & 0.38 & 0.001 & 0.13 & 0.05 & 0.67 \\
\hline Locus of control & -0.50 & -0.46 & $<0.001$ & -0.32 & -0.29 & 0.016 \\
\hline $\mathrm{R}^{2}$ & & & & 0.43 & & \\
\hline Adjusted $\mathrm{R}^{2}$ & & & & 0.38 & & \\
\hline
\end{tabular}

functional limitations. According to these researches, women tend to resume household activities immediately after hospital discharge and perceive the disruption in their independence and family's functioning as a cause of stress, anxiety, lowered self-esteem and guilt. Domestic and family demands are also perceived by women as a higher priority than the attendance to cardiac rehabilitation which can explain their low participation rates at CR [14].

The role of social support is widely recognized as an important prognostic factor and it has been found to have a positive effect on mental and physical health outcomes [13]. Older woman with heart disease are more likely to be widowed and might benefit from support groups, family and friends. Group-based programs may facilitate instrumental and social support for elderly woman and may promote adherence and healthy behaviours [20]. Older cardiac women of this study also reported needs related to assistance and treatment, such as the need to have more information about the diagnosis and the future conditions, the need to be more reassured by clinicians and that physical symptoms are better controlled. This result can be related to their need to understand whether will be possible to early resume their family role and independence at home. These findings are in line with a recent study of Pianese and coll. [40] which showed that an important area of needs among patients with advanced heart failure was the knowledge and the prognosis of their disease, the awareness of alarm and worsening symptoms, and the need of a better communication and information exchange. Finally, some patients expressed the need to have more economic-insurance information related, for example, to tickets and invalidity, which suggests to also paying attention to instrumental and financial needs.

The second aim of this study was to explore whether patients aged 65-75 and those aged $>75$ years differ in psychosocial characteristics and needs. Previous studies reported the benefits of surgical interventions and cardiac rehabilitation on risk reductions, improvements in exercise capacity, quality of life and psychosocial outcomes among elderly cardiac patients $[2,7,9,41]$. We found that results of psychological questionnaires did not differ in the two age groups of patients, which means that women at an advanced age ( $>65)$ share similar psychosocial issues and problems, and may benefits from psychosocial interventions which address common domains, such as the need of more information related to their diagnosis and prognosis, social support, emotional distress, cognitive functioning and socioeconomic status [2, 20, 40]. In this sample of the study, women aged over 75 years did not live alone and they seem to do not experience social isolation, lower self-esteem or greater symptoms of depression and anxiety compared to patients aged under 75 years. These findings may be explained by the important value also given by elderly women to their family's functioning and their tendency to regain their role as homemaker as soon as possible [20]. This perceived responsibility in the family's functioning and in the home duties might be a protective factor against feeling of uselessness and depressive symptoms; this result also supports the importance of a rehabilitative program which includes occupational therapy aimed at facilitating older women's return to their activities of daily living, with particular regard to household activities.

Finally, we explored factors associated with older patients' mental health status in order to develop cardiac rehabilitation programs designed specifically to meet psychosocial needs of women after heart surgery. Results showed that anxiety and locus of control were the best predictors of mental health among older women during their cardiac rehabilitation. Symptoms of anxiety and depression are common among patients with CVD and are associated with an increased risk of impaired health status and mortality [42, 43]. The hospitalization can cause feelings of anxiety, emotional distress and worries related to the success of the surgery and the adaptation to the changed situation. A study of Gallagher and McKinley [42] showed that being female and an older age were associated with higher levels of anxiety in patients undergoing coronary artery bypass surgery. The authors recommended the importance of identifying stressors associated with anxiety for cardiac patients in order to develop early 
and effective interventions for reducing uncertainty, improving their sense of control over the illness, promoting coping and providing psychological support [13]. In our study, locus of control also exerted an important impact on mental health. Previous studies showed that internal locus of control was associated with improved adherence, successfully coping with stress, positive psychological adjustment to illness, less cardiac events and physiological distress on the heart among cardiac patients [44, 45, 4]. Perceived control over own illness and life can help the process of recovery, the personal well-being and success [14]. In other words, patients who believed that they had control over their lives and who perceived to influence illness outcomes through their behavior, were more like to report positive mental health during the rehabilitation process.

These findings have important implications for rehabilitation programs of cardiac women aged $\geq$ 65 years. Older women after cardiac surgery need tailored rehabilitative interventions able to meet their specific necessities such as the management of anxiety symptoms and loss of control, the need to regain their family role as soon as possible, the need of more information concerning their diagnosis and prognosis and emotional support. The main limitations of this study include the small sample size which was recruited from a single cardiac rehabilitation unit and the cross-sectional design which does not allow to describe causal relationships. Furthermore, results from the Needs Evaluation Questionnaire did not refer to the total sample of 74 women but are limited to 60 participants of the study. However, this was an exploratory research which aimed to focus on a current issue of the cardiac rehabilitation which needs to be deeply explored by further research. Specifically, longitudinal design studies exploring the effectiveness of tailored cardiac interventions for older women are needed in order to improve clinical practice and patients' health outcomes.

\section{Riassunto}

Background. I recenti progressi nei protocolli terapeutici hanno determinato un aumento della prevalenza della patologia cardiaca in una popolazione di età avanzata. Precedenti studi hanno mostrato che, in particolare, le donne cardiopatiche presentano esiti più sfavorevoli in termini di salute fisica e psichica rispetto agli uomini. Il principale obiettivo del presente studio è la valutazione dei bisogni psicologici e dei fattori che favoriscono un positivo stato di salute mentale in donne cardioperate di età $\geq 65$ anni.

Metodi. Hanno partecipato allo studio 74 donne di età $\geq 65$ anni afferenti ad un' unità di riabilitazione cardiaca del nord Italia a seguito di un intervento cardiochirurgico. Una psicologa ha somministrato ad ogni paziente, mediante un' intervista, questionari psicologici che valutano il deterioramento cognitivo, i bisogni psicologici, l'ansia, la depressione, lo stato di salute fisico e mentale e l'autostima.

Risultati. Le principali aree di bisogno psicologico emerse sono quelle relative al supporto rela- zionale ed emotivo, assistenza e cura, informazioni inerenti la diagnosi e le condizioni future e aspetti economico-assicurativo. Le analisi di regressione lineare multivariata hanno mostrato che i fattori significativamente associati con lo stato di salute mentale delle pazienti sono l'ansia $(p=0.01)$ e il locus of control $(p=0.01)$.

Conclusioni. Per migliorare lo stato di benessere psicologico delle donne cardioperate in età avanzata è importante offrire interventi riabilitativi specifici per questa fascia di età in grado di soddisfare i loro bisogni, come la gestione dei sintomi ansiosi e di senso di perdita di controllo, il bisogno di riprendere il proprio ruolo familiare, di avere più informazioni relative alla propria diagnosi e prognosi e maggiore supporto emotivo.

Parole chiave: donne over 65, cardiochirurgia, bisogni psicologici, salute mentale, riabilitazione cardiaca.

\section{References}

1. Kattainen A, Salomaa V, Härkänen $\mathrm{T}$ et al. Coronary heart disease: from a disease of middle-aged men in the late 1970 s to a disease of elderly women in the 2000s. Eur Heart J 2006; 27: 296-301.

2. Williams MA, Fleg JL, Ades PA et al. Secondary prevention of coronary heart disease in the elderly (with emphasis on patients $\geq 75$ years of age). Circulation 2002; 105: 17351743.

3. Nichols M, Townsend P, Luengo-Fernandez R, Leal J, Scarborough P, Rayner M. European Cardiovascular Statistics 2012. European Heart Network, Brussels, European Society for Cardiology, Sophia Antipolis, 2012.

4. Mannsverk J, Wilsgaard T, Njølstad I et al. Age and gender differences in incidence and case fatality trends for myocardial infarction: a 30-year follow-up. The Troms $\emptyset$ Study. Eur J Prev Cardiol 2012; 19(5): 927-934.

5. Balady GJ, Williams MA, Ades PA et al. Core components of cardiac rehabilitation/secondary prevention programs: 2007 update. Circulation 2007; 115: 2675-2682.

6. Yonezawa R, Masuda T, Matsunaga A et al. Effects of phase II cardiac rehabilitation on job stress and health-related quality of life after return to work in middle-aged patients with acute myocardial infarction. Int Heart $J$ 2009; 50: 279-290.

7. Hage C, Mattson E, Stahle A. Long-term effects of exercise training on physical activity level and quality of life in elderly coronary patients: a three to six year follow-up. Physiotherapy Res Int 2002; 8: 13-22.

8. Onishi T, Shimada K, Sato H et al. Effects of phase III cardiac rehabilitation on mortality and cardiovascular events in elderly patients with stable coronary artery disease. Circ J 2010; 74: 709-714.

9. Lavie CJ, Milani RV. Benefits of cardiac rehabilitation and exercise training in elderly women. Am J Cardiol 1997; 79(5): 664-666.

10. Stenlund T, Lindtröm, M Granlund, G Burell. Cardiac rehabilitation for the elderly: Qui Gong and group discussions. Eur J Cardiovasc Prev Rehabil 2005; 12: 5-11.

11. Linden W, Phillips MJ, Leclerc J. Psychological treatment of cardiac patients: a meta-analysis. Eur Heart $J$ 2007; 28: 2972-2984.

12. Orth-Gomer K, Schneiderman Wang HX, Wallin C, Blom M, Jernberg T. Stress reduction prolongs life in women with coronary heart disease (SWITCHD). Circ Cardiovasc Qual Outcomes, 2009; 2: 25-32.

13. Grace SL, Abbey SE, Zachary MS, Irvine J, Franche RL, Steward DE. Cardiac rehabilitation I: review of psychosocial factors. Gen Hosp Psychiat 2002; 24: 121-126. 
14. Clark AM, King-Shier KM, Thompson DR et al. A qualitative systematic review of influences on attendance at cardiac rehabilitation programs after referral. Am Heart $J$ 2012; 164: 835-845.

15. Jackson L, Leclerc J, Erskine Y, Linden W. Getting the most out of cardiac rehabilitation: a review of referral and adherence predictors. Heart 2005; 91: 10-14.

16. Bute BP, Mathew J, Blumenthal JA et al. Female gender is associated with impaired quality of life 1 year after coronary artery bypass surgery. Psychosom Med 2003; 65: 944-951.

17. Halm MA, Penque S. Heart failure in women. Prognostic Cardiovasc Nurs, 2000; 15(4): 121-123.

18. King K. Emotional functional outcomes in women with coronary heart disease. J Cardiovasc Nurs 2001; 15(3): 54-70.

19. Norris CM, Ghali WA, Galbraith PD et al. Women with coronary artery disease report worse health related quality of life outcomes compared to men. Health Qual Life Out 2004; 5: 2-21.

20. Davidson PM, Daly J, Hancock K et al. A literature review and identification of a research agenda in older women (Review). Eur J Cardiovasc Nurs, 2003; 2(4): 255-264.

21. Tolmie EP, Lindsay GM, Kelly T et al. Are older patients' cardiac rehabilitation needs being met? J Clin Nurs 2009; 18: 1878-1888.

22. Folstein MF, Folstein SE, McHugh PR. Mini-mental state - practical method for grading cognitive state of patients for clinician. J Psychiat Res 1975; 12: 189-198.

23. Grigoletto F, Zappalà G, Anderson DW, Lebowitz BD. Norms for the Mini-Mental State Examination in a healthy population. Neurology 1999; 53(2): 315-320.

24. Lezak MD, Howieson DB, Loring DL. Neuropsychological assessment. $4^{\text {th }}$ ed. New York NY: Oxford University Press, 2004.

25. Tamburini M, Gangeri L, Brunelli C et al. Assessment of hospitalized cancer patients' needs by the Needs Evaluation Questionnaire. Ann Oncol 2000; 11: 31-37.

26. Annunziata MA, Muzzati B, Altolè GA. A contribution to the validation of the Needs Evaluation Questionnaire (NEQ): a study in the Italian context. Psychooncol 2009; 18: 549-553.

27. Moroni L, Bettinardi O, Vidotto G, et al. Anxiety and Depression Short Scale: norms for its use in rehabilitation. Monaldi Arch Chest Dis, 2006; 66: 255-263.

28. Vidotto G, Moroni L, Burro R et al. A revised short version of the depression questionnaire. Eur J Cardiovasc Prev Rehab 2010; 17: 187-197.

29. Bertolotti G, Michielin P, Vidotto G, Zotti AM, Sanavio E. Depression Questionnaire (DQ). In: Nezu AM, Ronan GF, Meadows EA, McKlure KS, ed. Practitioner's guide to empirical based measures of depression. Norwell MA: Kluwer Academic/Plenum Publishers, 2000.

30. Vidotto, G., Bertolotti, G. Una valutazione base dell'ansia di stato. La versione ridotta dello STAI-X1. Boll Psicol Appl, 1991; 198: 33-40.
31. Spielberg, CD, Gorsuch RL, Lushene RE. The State-Trait Anxiety Inventory (STAI) Test Manual for Form X. Palo Alto: Consulting Psychologist Press, 1970. (tr. it.: a cura di Lazzari R, Pancheri P. S.T.A.I. Questionario di autovalutazione dell'ansia di stato e di tratto. Firenze: Organizzazioni Speciali, 1980).

32. Ware JE, Kosinski M, Keller SD. A 12-Item Short-Form Health Survey: construction of scales and preliminary tests of reliability and validity. Med Care 1996; 34: 220-233.

33. Apolone G, Mosconi P, Quattrociocchi L. Questionario sullo stato di salute SF-12. Versione Italiana. Milano: Guerini e Associati Editore, 2001.

34. Ware J, Snow K, Kosinski M, Gandek B. SF-36 Health Survey: Manual and Interpretation Guide. Boston, Mass: The Health Institute, New England Medical Centre, 1993.

35. Craig AR, Franklin JA, Andrews G. A scale to measure locus of control of behaviour. Brit J Med Psychol 1984; 57: 173-180.

36. Farma, T, Cortinovis, I. Un questionario sul "Locus of Control": suo utilizzo nel contesto italiano. Milano: Ricerca in psicoterapia, 2001.

37. Rosenberg M. Society and the adolescence self-image. Princeton NJ: Princeton University Press, 1965.

38. Prezza M, Trombaccia FR, Armento L. La scala dell'autostima di Rosenberg: traduzione e validazione italiana. Boll Psicol Appl, 1997; 223: 35-44.

39. Orth-Gomer K, Wamala SP, Horsten M, SchenckGustafsson K, Schneiderman N, Mittleman MA. Marital stress worsens prognosis in women with coronary heart disease: The Stockholm female coronary risk study. JAMA 2000; 284 (23): 3008-14.

40. Pianese M, De Astis V, Griffo R. Analisi dei bisogni assistenziali in ambito domiciliare del paziente con scompenso cardiaco avanzato. Monaldi Arch Chest Dis 2011; 76: 74-80.

41. Chocron S, Tatou E, Schjoth B et al. Perceived health status in patients over 70 before and after open heart operations. Age Ageing 2000; 29: 329-334.

42. Gallagher R, McKinley S. Stressors and anxiety in patients undergoing coronary artery bypass surgery. Am J Crit Care 2007; 16: 248-257.

43. Tully PJ, Baker RA, Turnbull D, Winefield H. The role of depression and anxiety symptoms in hospital readmission after cardiac surgery. J Behav Med 2008; 31: 281-290.

44. Weinstein SE, Quigley KS, Mordkoff JT. The impact of control and effort on cardiovascular reactivity during a laboratory stress task. Psychophysiology 2002; 39: 591-598.

45. Helgeson VS and Fritz HL. Cognitive adaptation as a predictor of new coronary events after percutaneous transluminal coronary angioplasty. Psychosom Med 1999; 61: 488-495.

46. Leong J, Molassiotis A, Marsh H. Adherence to health recommendations after a cardiac rehabilitation programme in post-myocardial infarction patients: the role of health beliefs, locus of control and psychological status. Clin Effect Nurs 2004, 8: 26-38. 